\title{
ALTRUISM AND ENVY IN CONTESTS: AN EVOLUTIONARILY STABLE SYMBIOSIS
}

\author{
KAI A. KONRAD
}

CESIFO WORKING PAPER NO. 825

CATEgory 1: Public FinANCE

DECEMBER 2002

\footnotetext{
An electronic version of the paper may be downloaded

- from the SSRN website: www.SSRN.com

- from the CESifo website: www.CESifo.de
} 


\title{
ALTRUISM AND ENVY IN CONTESTS: AN EVOLUTIONARILY STABLE SYMBIOSIS
}

\begin{abstract}
Altruists and envious people who meet in contests are symbionts. They do better than a population of narrowly rational individuals. If there are only altruists and envious individuals, a particular mixture of altruists and envious individuals is evolutionarily stable.
\end{abstract}

Keywords: altruism, envy, contests, evolutionary stability.

JEL Classification: C72, D64, D74.

\author{
Kai A. Konrad \\ $W Z B$ \\ Reichpietschufer 50 \\ 10785 Berlin \\ Germany \\ kkonrad@wz-berlin.de
}

I thank Helmut Bester and a referee for very helpful comments. The usual caveat applies. 


\section{Introduction}

Piecemeal evidence suggests that altruism but also envy are widespread phenomena. ${ }^{1}$ They refer to the concept that an individual cares about the wellbeing of another individual. Whether the individual is altruistic or envious depends on the sign of this caring. Altruism and envy provide incentives for individuals to deviate from what is sometimes called their narrow self-interest and to do things because they affect the well-being of other individuals.

Consider, for instance, altruism and envy among participants in a contest. When two players contest for a prize that is allocated to the player who has made the highest effort, they know that their effort also affects the win probability of their opponent. Accordingly, an altruist is less interested in winning, and an envious person may be more interested in winning than a narrowly self-interested individual.

Similar to Bester and Güth (1998), we distinguish between utility functions that describe an ordering of outcomes according to the individuals' preferences, and their material payoffs. Utility and material payoff are identical for a narrowly self-interested individual (i.e., someone who is free of altruism or envy). They differ for altruists and for envious individuals. The distinction between utility and material payoff is inspired by sociobiology. There, material payoff determines the reproductive fitness of an individual and may differ from the individual's subjective feelings of well-being.

Intuitively, altruistic or envious individuals should achieve a lower expected material payoff than individuals who are not altruistic or envious. In this paper we show that an equilibrium exists in which a share of agents is

\footnotetext{
${ }^{1}$ For a broader discussion of the economics of envy and a brief literature survey see, e.g., Mui (1995). Altruism has been discussed even more widely. Key references are Becker (1974, 1976), Lindbeck and Weibull (1988) and Bruce and Waldman (1990).
} 
altruistic toward their opponent in a contest, and another share of agents is envious, such that the material payoffs of both the envious and the altruistic players are strictly higher than in a situation in which emotions like envy and altruism are both absent.

Further, we consider the evolutionary stability of such equilibria. Evolutionary stability of altruism has been considered in the context of private provision of public goods. Bergstrom (1995) and Bergstrom and Stark (1993) consider a particular effect of altruism between siblings that may stabilize altruism. When an individual grows up in a group of siblings, he may do better as an egoist than as an altruist. However, an egoist will have offspring that consists of egoists, whereas altruists have offspring that consists of altruists. Hence, the offspring of altruists will do better as a group than the offspring of an egoist. Lohmann, Oechssler and Wärneryd (2001) consider a different, group-selection argument. ${ }^{2}$

Bester and Güth (1998) consider individuals that are matched pairwise and are forced to play some prisoners' dilemma game. Individuals can observe whether their match is an altruist or an egoist. Due to their altruism they treat altruists differently from how they treat narrowly selfish individuals,

\footnotetext{
${ }^{2}$ In Lohmann, Oechssler and Wärneryd (2001) altruists are characterized by a higher willingness to contribute to a group-specific public good. Randomly matched groups with (at least one) altruist do better than groups without altruists. Because altruists make the contributions to the public good, their fitness is lower than that of a non-altruist from the same group. However, the altruists' fitness can be higher than the average fitness of a randomly selected non-altruist who may be allocated to a group that may or may not have an altruist. This is the case if the share of altruists is very low, because in this case nonaltruists are likely to be in groups in which no altruist is present. And, as individuals are randomly matched in each period, this average fitness is the relevant one for non-altruists to compare it with an altruist's fitness.
} 
internalizing part of the mutual benefits of cooperation. They show that this strategic effect is sufficient to stabilize a population in which individuals are altruists. Their approach is different, but the result is much in line with Frank's $(1987,1988)$ analysis of the commitment value of particular emotions like hate, love, or altruism.

Both in the approaches by Frank $(1987,1988)$ and by Bester and Güth (1998) the assumption is crucial for the evolutionary stability of altruism that the true type of a co-player can be observed, at least with some strictly positive probability. We depart from this assumption and consider a set-up in which a player cannot observe the co-player's type. A player's own type (envious or altruistic) is strictly private information. The fact that altruism can be evolutionarily stable in this incomplete information framework reveals that a different mechanism to stabilize altruism is at work. Altruism and envy are optimal behavior given that co-players show the opposite type of behavior. Altruism pays if co-players are envious, and envy pays if co-players are altruists. The relationship between these types has the character of a symbiosis.

In the framework considered here a population with a given mix of envious and altruistic individuals can be invaded by a narrowly selfish population. Accordingly, the result may seem weaker than, for instance, the results in Bester and Güth (1998). However, the paper also considers much weaker assumptions regarding individuals' information about their co-players' preferences. Also the emphasis of this paper is different: the paper reveals an interesting relationship between altruism and envy: symbiosis. We analyse this relationship in an important but specific type of interaction: individuals are randomly matched and enter a pairwise contest: they spend effort to win a prize and the contestant's win probability is a function of his and his 
opponent's effort.

The paper proceeds as follows. First we analyse the contest with two types of contestants and incomplete information. The two types can be interpreted as altruists and as players who are envious about the opponent winning the prize. For this analysis the probability beliefs of the two contestants about their opponent's type are considered exogenous and symmetric. ${ }^{3}$ Then we consider this contest game as the state game in the evolutionary game. We show that, for given degrees of altruism and envy, there is an evolutionarily stable equilibrium share of altruistic and envious players, whereas a population that consists of altruists only (or envious individuals only) can be invaded by envious (altruistic) individuals.

\section{Contests with altruism and envy}

Consider the following state game. There is an infinitely large set $I$ of players with measure 1, called the population. Individuals from this set are pairwise randomly matched. Matched players (say, 1 and 2) enter a contest. In this contest players make simultaneous contest efforts $e_{1}$ and $e_{2}$. The player who chooses the higher effort is awarded a prize that has a material value equal to $B$, which is the same for both players. The prize is allocated according to the flip of a coin in case both players make the same effort, where the efforts and the prize are measured in units of a homogenous universal good. The expected amount of this good obtained net of contest effort by player 1 is called the material payoff of player 1 and is equal to

$$
\pi_{1}=p_{1}\left(e_{1}, e_{2}\right) B-e_{1}
$$

\footnotetext{
${ }^{3} \mathrm{~A}$ few papers that consider contests with incomplete information are Glazer and Hassin (1988), Amann and Leininger (1996), and Baye, Kovenock and deVries (1998).
} 
with

$$
p_{1}\left(e_{1}, e_{2}\right)=\left\{\begin{array}{c}
1 \quad \text { for } e_{1}>e_{2} \\
1 / 2 \text { for } e_{1}=e_{2} \\
0 \quad \text { for } e_{1}<e_{2}
\end{array},\right.
$$

and similarly for player 2 with $p_{2}=1-p_{1}$. For instance, the material payoff could be the player's expected income net of contest expenditure. It would also be the payoff of a risk-neutral player who is neither envious nor altruistic, but is what is sometimes called narrowly selfish. A different consideration motivating this definition is that, in a natural environment the material payoff is what determines the probability of survival and reproductive success (reproductive fitness) of a player.

In addition to the material payoff in (1), emotions such as altruism or envy may determine individuals' subjective well-being or utility. Consider player 1 in the contest. If he is an altruist his utility is

$$
U_{A}=p_{1} B+\left(1-p_{1}\right) \alpha B-e_{1},
$$

with $\alpha \in(0,1)$ and he chooses effort to maximize this utility. The altruist has some pleasure even if his opponent wins the prize. However, this pleasure is only $\alpha$ times the pleasure he has if the prize is awarded to himself. The constant $\alpha$ is the altruism-weight and is considered exogenous throughout the paper. This valuation must be distinguished from the material payoff (1). The altruist's utility can be re-written as

$$
U_{A} \equiv \alpha B+p_{1} V_{A}-e_{1} \text {, with } V_{A} \equiv(1-\alpha) B
$$

Since $\alpha B$ is a constant with respect to effort choices, an altruist acts as if the prize he can win in the contest is $V_{A}$ and somewhat smaller than $B$.

Alternatively, player 1 may be envious. He suffers if his opponent wins the prize. His utility function is $p_{1} B-\left(1-p_{1}\right) \beta B-e_{1}$ with $\beta \in(0,1)$ the 
weight of envy in the player's objective function and can be written as

$$
U_{E} \equiv-\beta B+p_{1} V_{E}-e_{1} \text { with } V_{E} \equiv(1+\beta) B
$$

The term $-\beta B$ is irrelevant for the players' effort choices. An envious player acts as if the prize he can win in the contest is somewhat larger than $B$.

In what follows we assume that players either exhibit altruism or envy, with given parameters $\alpha$ and $\beta$. We solve for the equilibrium effort choices in contest games in which two players meet. Each player knows whether he is an altruist or an envious person, but does not know the type of his opponent. However, the share of altruists in the population, and the random matching process are common knowledge. Hence, each player knows that his opponent is an altruist with probability $\gamma$ and envious with probability $(1-\gamma)$. In the contest each player chooses an effort that maximizes his utility, given the player's expectations about the other player's choice. The equilibrium contest efforts are necessarily in mixed strategies and are characterized in the following proposition.

Proposition 1 Consider a contest with the contest success function (2) with two contestants. A contestant is an altruist with altruism weight $\alpha$ or is envious with envy weight $\beta$. Each contestant knows his type and knows that the other contestant is a random draw from a population I with a share $\gamma$ of altruists and a share $(1-\gamma)$ of players exhibiting envy. The cumulative density functions (c.d.f.s) of efforts

$$
F_{A}(e)=\left\{\begin{array}{ccc}
0 & \text { for } & e \leq 0 \\
e /\left(\gamma V_{A}\right) & \text { for } & e \in\left(0, \gamma V_{A}\right) \\
1 & \text { for } & e \geq \gamma V_{A}
\end{array}\right.
$$


for altruists and

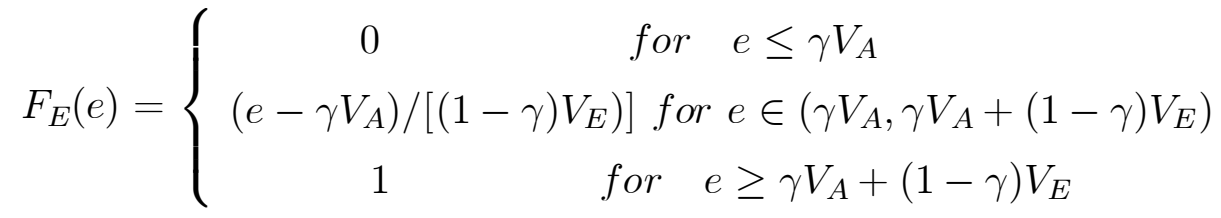

for envious players constitute the unique Bayesian Nash equilibrium.

Proof. The contest equilibrium for the case of incomplete information has been characterized in more general terms by Amann and Leininger (1996) for the case of a continuous distribution of types without mass points. The result in Proposition 1 is for a binary distribution of types, but could be derived along similar lines. It is straightforward to verify that (6) and (7) constitute an equilibrium. Suppose player 2 who is an altruist with probability $\gamma$ and envious with probability $(1-\gamma)$ follows these strategies, depending on his type. If player 1 is an altruist, he has utility $E U_{A}=\alpha B$ for all choices of effort $e_{A} \in\left[0, \gamma V_{A}\right]$ and lower expected utility for any $e_{A}>\gamma V_{A}$. If player 1 is envious, he has utility equal to $E U_{E}=\gamma\left(V_{E}-V_{A}\right)-\beta B$ for all $e_{E} \in\left[\gamma V_{A}, \gamma V_{A}+(1-\gamma) V_{E}\right]$, and lower utility for all non-negative effort choices outside this interval.

For uniqueness, we only give a heuristic argument that also helps to make this equilibrium outcome more intuitive. It is easy to see that the equilibrium must be in mixed strategies ${ }^{4}$ with no mass points other than (possibly) at

\footnotetext{
${ }^{4}$ Suppose the equilibrium were in pure strategies. Let $\left(e_{1}^{*}, e_{2}^{*}\right)$ be such an equilibrium. Clearly, $e_{1}^{*}=e_{2}^{*}=0$ is not an equilibrium. Let $e_{1}^{*}>0$. Then the optimal effort choice of contestant 2 is $e_{2}\left(e_{1}^{*}\right)=0$ or $e_{2}\left(e_{1}^{*}\right)=e_{1}^{*}+\epsilon$ for small but positive $\epsilon$. Then player 1's choice of $e_{1}^{*}>0$ is not his best effort choice. If $e_{2}=0$, player 1 can do better by any
} 
$e=0.5$

Consider an altruist's expected utility from some effort choice: $E U_{A}=$ $\gamma V_{A} F_{A}\left(e_{A}\right)+(1-\gamma) V_{A} F_{E}\left(e_{A}\right)+\alpha B-e_{A}$. A marginal increase in his effort choice $e_{A}$ yields no increase in expected utility if

$$
\frac{d E U_{A}}{d e_{A}}=\gamma V_{A} F_{A}^{\prime}\left(e_{A}\right)+(1-\gamma) V_{A} F_{E}^{\prime}\left(e_{A}\right)-1=0 .
$$

Similarly, an envious person is indifferent as regards a marginal increase in his effort choice, $e_{E}$, if

$$
\frac{d E U_{E}}{d e_{E}}=\gamma V_{E} F_{A}^{\prime}\left(e_{E}\right)+(1-\gamma) V_{E} F_{E}^{\prime}\left(e_{E}\right)-1=0
$$

Equations (8) and (9) are incompatible: $\frac{d}{d e} E U_{A}<\frac{d}{d e} E U_{E}$ for any given effort level $e=e_{A}=e_{E}$. Hence, envious players always choose higher effort than altruistic players.

Making use of this result, (8) reduces to $F_{A}^{\prime}(e)=\frac{1}{\gamma V_{A}}$ in some range, $e \in$ $\left[0, D_{A}\right]$, and, from (9), for envious persons, $F_{E}^{\prime}=\frac{1}{(1-\gamma) V_{E}}$ in some range, $e \in$ $\left[D_{A}, D_{E}\right]$. This shows that the effort choices must be uniformly distributed along the respective intervals. It remains to determine these intervals.

Note that there is also no mass point at $e_{A}=0$ : If an altruist spends exactly zero effort, his expected utility is $\frac{\gamma V_{A}}{2} F_{A}(0)$. Comparison of this utility with the utility for $e_{A}=0+\epsilon$ for $\epsilon \rightarrow 0$ requires that $F_{A}(0)=0$ in the choice $e_{1} \in\left(0, e_{1}^{*}\right)$. If $e_{2}=e_{1}^{*}+\epsilon$, then either $e_{1}=0$ or $e_{1}=e_{2}+\epsilon$ yields higher utility than $e_{1}^{*}$.

${ }^{5}$ Mass points for $e>0$ can be ruled out by the following reasoning (Baye, Kovenock and deVries 1996). Suppose player 2 has a mass point at $\hat{e}>0$. Then any effort $e_{1} \in$ $[\hat{e}, \hat{e}-\delta]$ has lower utility for player 1 than, e.g., $e_{1}=\hat{e}+\delta$, for sufficiently small postive $\delta$. Accordingly, player 1 never chooses effort from this interval. This in turn makes $e_{2}=\hat{e}$ suboptimal for player 2. Player 2's utility is higher, for instance, for $e_{2}=\hat{e}-\delta$. Therefore, player 2 cannot have a mass point at $\hat{e}$ in the equilibrium. 
equilibrium. Note also that, for reasons analogous to the ones that rule out mass points at some $e>0, F_{A}^{\prime}(e)>0$ for $e=0$. Further, an altruist must be indifferent between bidding $D_{A}$ or 0 . If he bids $D_{A}$ he spends effort equal to $D_{A}$ and wins with probability $\gamma$ a prize equal to $V_{A}$ : he wins if the opponent is an altruist, because altruists make bids lower than $D_{A}$ with probability 1 , and he loses if the opponent is envious, because envious players make bids higher than $D_{A}$ with probability 1 , and $\gamma$ is precisely the probability that the opponent is an altruist. If he bids zero he never wins but has no effort. Hence, $\gamma V_{A}-D_{A}=0$ must hold and this yields $D_{A}=\gamma V_{A}$ which, together with $F_{A}^{\prime}(e)=1 /\left(\gamma V_{A}\right)$ for $e_{A} \in\left[0, D_{A}\right]$ determines (6).

Further, $D_{E}=\gamma V_{A}+(1-\gamma) V_{E}$ can be found as the implicit solution of $\int_{D_{A}}^{D_{E}} 1 /\left[(1-\gamma) V_{E}\right] d e$, using $D_{A}=\gamma V_{A}$. This concludes the proof.

Proposition 1 describes the two types' mixed equilibrium strategies. For $\gamma=0$ or $\gamma=1$ the equilibrium converges to the equilibrium of the symmetric first-price all-pay auction as in Baye, Kovenock and deVries (1996). In the incomplete information equilibrium, for $\gamma \in(0,1)$, bids of the types are sorted according to the order of their valuations of the prize. This parallels the results in Amann and Leininger (1996) who consider a smooth distribution of types. The equilibrium c.d.f.'s in Proposition 1 can be used to calculate the expected values of utility: $E U_{A}=\alpha B$ for altruists and $E U_{E}=\gamma\left(V_{E}-\right.$ $\left.V_{A}\right)-\beta B$ for envious players.

For given $\gamma$ the material payoffs can be calculated similarly and are

$$
\pi_{A}=\frac{\gamma}{2} \alpha B
$$

for altruists and

$$
\pi_{E}=\gamma \alpha B-\frac{(1-\gamma)}{2} \beta B
$$

for envious players. 
It is interesting to contrast the payoffs of the contest game with envious and altruistic players with the payoffs of the same type of contest if all players behave narrowly selfish and simply maximize their material payoffs. $\pi_{A}=\pi_{E}=0$ for $\alpha=\beta=0$. Note also that altruism, but not envy is needed to generate positive payoffs. ${ }^{6}$

In this contest, the share of altruists determines whether the material payoff of altruists is higher or lower than envious players' payoff. In a next step we will assume that populations at a given stage consist of given shares of altruistic and envious players that behave as characterized in Proposition 1. However, the shares of altruists and envious players may be determined endogenously. For instance, if one type of preference systematically yields a higher equilibrium material payoff than the other, it seems to be plausible that the share of this type in the population increases. If this process runs for some time, the whole population may consist of one type, and the mutual advantage of altruists and envious players from a heterogenous population may disappear. Alternatively, there may be some kind of predator-prey equilibrium in which a population is stabilized in a situation in which a share of individuals is altruistic and the other share of the population is envious. This question is addressed in the next section.

\footnotetext{
${ }^{6}$ For complete information (observability of one's opponent's type) the material payoffs in the equilibrium can be calculated using the results of Baye, Kovenock and deVries (1996) on the contest equilibrium for asymmetric valuations of contest prizes. This yields $\pi_{A}=\left[\frac{\gamma}{2}+\frac{1-\gamma}{2} \frac{1-\alpha}{1+\beta}\right] \alpha B$ and $\pi_{E}=\gamma\left[\left(1-\frac{V_{A}}{2 V_{e}}\right) B-\frac{V_{A}}{2}\right]+(1-\gamma) \frac{B-V_{E}}{2}$. Hence, the outcome is qualitatively similar. However, we consider the incomplete information case in order to highlight that it is not the differential treatment that altruists and egoists receive that will stabilize altruism.
} 


\section{The population game}

The contest game in section 2 can be seen as a single stage game in a dynamic (evolutionary) context in which the share of altruists is endogenous and changes according to the relative success of envious players compared to altruists, measured by their relative material payoffs and we can ask the question whether there is a distribution of types that emerges in the long run if the shares grow according to some monotonic evolutionary dynamics.

Note that the 'indirect' evolutionary approach is analysed here: individuals behave fully rational given their own preferences, but evolutionary selection operates on the set of feasible preferences that define the 'types', and the fitness of a particular preference type is determined by the material payoff which this type earns given the population shares of types, and given that each individual of each type behaves fully rationally. ${ }^{7}$

Consider again the set $I$ with a continuum of players with mass 1 - the population. Suppose the contest game with the equilibrium that is characterized in Proposition 1 is repeatedly played in this population: in each round all players are randomly matched and play a contest as in section 2 . There are two feasible types of players: individuals who have altruist preferences and maximize their expected utility as in (4) in the contest, and envious individuals who maximize (5). Let $\gamma_{t}$ and $1-\gamma_{t}$ be the population shares of altruists and envious individuals in a given period $t$. Suppose that types' growth rates are described by some monotonic evolutionary process where types' growth rates positively depend on their average period material payoffs. The following proposition holds:

\footnotetext{
${ }^{7}$ Güth and Yaari (1992), Bester and Güth (1998) and Huck and Oechssler (1999) and others have used this approach. Some detailed explanations and comparisons to a direct approach in which types are defined by their strategies is in Bester and Güth (1998).
} 
Proposition 2 There are three stationary distributions of altruists and envious persons if types' growth rates positively depend on their average material payoff: $\gamma=0, \gamma=1$ and

$$
\gamma=\frac{V_{E}-B}{V_{E}-V_{A}}=\frac{\beta}{\alpha+\beta} \equiv \gamma^{*} .
$$

Starting from some $\gamma_{0} \in(0,1)$, only the stationary distribution $\gamma^{*}$ is reached in the long run. The material payoff of each player in this equilibrium is

$$
\pi^{*}=\frac{\left(V_{E}-B\right)\left(B-V_{A}\right)}{2\left(V_{E}-V_{A}\right)}=\frac{\alpha \beta}{2(\alpha+\beta)} B .
$$

The stationarity of $\gamma=0$ and $\gamma=1$ is obvious. Consider now $\gamma^{*}$. The material payoff of an altruist is equal to $\pi_{A}=\gamma\left(B-V_{A}\right) / 2$. The payoff of an envious person is $\pi_{E}=B \frac{1+\gamma}{2}-\gamma V_{A}-\frac{1-\gamma}{2} V_{E}$. These functions are depicted in Figure 1. For $\gamma \in(0,1)$ the share of altruists grows for $\gamma<\beta /(\alpha+\beta)$ and decreases for $\gamma>\beta /(\alpha+\beta)$ and stays constant for $\gamma=\beta /(\alpha+\beta) \equiv \gamma^{*}$. The value of $\pi^{*}$ is confirmed by substituting $\gamma^{*}$ in $\pi_{A}$ or $\pi_{E}$.

Intuitively, egoists and altruists both gain in their material payoffs from the existence of other altruists, because altruists do not spend much effort and leave some rent for their rivals. This gain is even larger for envious individuals, because their envy makes them aggressive in the contest. This yields an advantage for envious players in a population that consists overwhelmingly of altruists. However, an envious individual's material payoff is more negative than an altruist's payoff if they contest against another envious rival. Hence, envious individuals do worse than altruists in a population with a large share of envious people.

In a society which consists of altruists and envious persons, in which social interaction takes the form of a contest neither the group of altruists nor the group of envious persons will outgrow the other if growth rates positively 


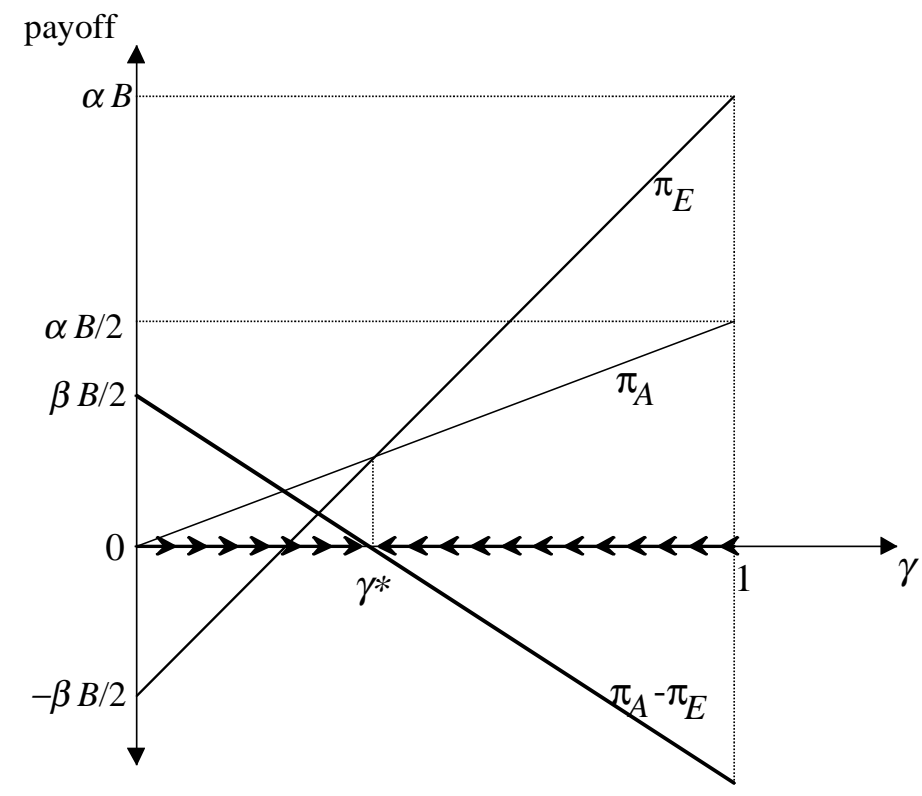

Figure 1: Payoff Differences and Evolutionary Dynamics

depend on material payoffs. Instead, there is a natural balance between the share of altruists and the share of envious individuals at which the material payoffs of both types are just equal, and to which the population would return if, for some exogenous reason, the share of altruists were changed. Note also that populations which consist of pure altruists $(\gamma=1)$ or of purely envious individuals $(\gamma=0)$ could be successfully invaded by envious or altruistic mutants.

Figure 1 also reveals the comparative static properties of the stationary distribution $\gamma^{*}$. A higher weight $\beta$ of envy implies a higher evolutionarily stable share of altruists and a higher weight $\alpha$ of altruism leads to a lower evolutionary stable share of altruists. Further, higher $\alpha \in(0,1)$ and higher $\beta \in(0,1)$ lead to higher material payoff in the evolutionarily stable equilibrium. 
One can also use the standard concept of ESS to obtain a result that is equivalent to Proposition 2. Samuelson (1997, pp. 41-42 and pp. 63-65) suggests that a distribution $\gamma \in[0,1]$ of two types with different preferences is interpreted as a mixed strategy, and then looks for the mixed strategy $\gamma$ that is ESS. $^{8}$ In the particular case here, being an altruist or an envious person are the pure strategies. Using this approach one can use the standard definition of ESS to characterize a mixed strategy $\gamma$ for given parameters $\alpha$ and $\beta$ that is a unique evolutionary stable strategy.

Proposition 2' Consider the set of mixed strategies that are characterized by the probability $\gamma \in[0,1]$ of behaving as an altruist, with exogenous weights $\alpha$ and $\beta$ of altruism and envy. The strategy $\gamma^{*}$ in (12) is an evolutionarily stable strategy.

For a proof suppose player 2 chooses $\gamma$. Then by (6) and (7), player 1's material payoff as an altruist is $\pi_{A}=\gamma\left(B-V_{A}\right) / 2$, and his payoff as an envious person is $\pi_{E}=B \frac{1+\gamma}{2}-\gamma V_{A}-\frac{1-\gamma}{2} V_{E}$. For $\gamma$ to be the symmetric equilibrium, player 1 must be indifferent with respect to his own choice. Hence, setting these payoffs equal and solving for $\gamma$ yields $\gamma^{*}=\frac{V_{E}-B}{V_{E}-V_{A}}$. Suppose a small group of mutants of mass $\epsilon$ invades, playing a mixed strategy $\hat{\gamma}$. Therefore, each player expects now to be matched with an altruist with probability $\bar{\gamma}=(1-\epsilon) \gamma^{*}+\epsilon \hat{\gamma}$. In this population the payoff of altruists is $\bar{\pi}_{A}=\bar{\gamma}\left(B-V_{A}\right) / 2$. The payoff of envious agents is $\bar{\pi}_{E}=\frac{1+\bar{\gamma}}{2} B-\bar{\gamma} V_{A}-\frac{1-\bar{\gamma}}{2} V_{E}$. The strategy $\gamma^{*}$ is evolutionarily stable if players

${ }^{8}$ Players typically do not actively randomize making a choice between altruism and envy in a stage prior to the actual contest stage and then behave as altruists or as envious persons in a later contest, but this is also not the appropriate interpretation of the analysis here. Samuelson (1997, p.64) relates the mapping of population shares into mixed strategies of each single agent to Harsanyi's purification model of mixed strategies. 
choosing $\gamma^{*}$ have a higher payoff in this population than players choosing $\hat{\gamma}$. That is, $\gamma^{*} \bar{\pi}_{A}+\left(1-\gamma^{*}\right) \bar{\pi}_{E}>\hat{\gamma} \bar{\pi}_{A}+(1-\hat{\gamma}) \bar{\pi}_{E}$ must hold, or, equivalently,

$$
\left(\gamma^{*}-\hat{\gamma}\right)\left(\bar{\pi}_{A}-\bar{\pi}_{E}\right)>0
$$

Condition (14) holds because $\left(\gamma^{*}-\hat{\gamma}\right)\left(\bar{\pi}_{A}-\bar{\pi}_{E}\right)=0$ at $\hat{\gamma}=\gamma^{*}, \frac{d}{d \hat{\gamma}}\left(\gamma^{*}-\hat{\gamma}\right)=$ $-1<0$, and $\frac{d}{d \hat{\gamma}}\left(\bar{\pi}_{A}-\bar{\pi}_{E}\right)=\epsilon \frac{V_{A}-V_{E}}{2}<0$.

If the growth rates of types are not a function of (10) or (11) but if the material payoff that drives the evolutionary dynamics is defined differently, the results may differ. The result in Proposition 2 qualitatively generalizes for some alternative definitions of material payoff. One interesting case would be a growth rate that depends on relative payoff

$$
r_{A}=\frac{\pi_{A}}{\gamma \pi_{A}+(1-\gamma) \pi_{E}} \text { and } r_{E}=\frac{\pi_{E}}{\gamma \pi_{A}+(1-\gamma) \pi_{E}} .
$$

Inserting and solving for the stationary solutions reveals that the same stationary solution $\gamma^{*}$ emerges.

An important aspect in this analysis was that players are unable to observe their opponent's type. A type that behaves narrowly selfishly (that is, a type with $\alpha=\beta=0$ ) could successfully invade a population with any mixture of altruists and envious individuals. If this type exists, the evolutionarily stable equilibrium consists of this type of rational players only. This negative result is due to the fact that we assume here that individuals cannot observe the type of their opponent, and therefore, the mechanisms that are at work in Bester and Güth (1998) and in Frank (1987, 1988), or the group selection mechanism outlined in Lohmann, Oechssler and Wärneryd (2001) are not at work here. 


\section{Conclusions}

If players are in an environment in which they frequently enter contests with little or no noise (as described by contest success functions as in (2)), they are better off (in terms of their material payoff) in a society in which individuals are either envious or altruistic. The benefit of behaving as an altruist is higher the larger the share of envious players, and the benefit of being envious is higher the larger the share of players who behaves altruistically. There is a share of altruists at which altruists and envious players have precisely identical material payoffs. Populations in which the material payoffs of altruists and envious players determine the future population shares have a tendency to end up with a specific mix of altruists and envious players. 


\section{References}

Amann E., Leininger W. (1996) Asymmetric all-pay auctions with incomplete information: the two-player case. Games and Economic Behavior 14: 1-18.

Baye M.R., Kovenock D., deVries C (1996) The all-pay auction with complete information. Economic Theory 8: 291-305.

Baye M.R., Kovenock D., de Vries C (1998) A general linear model of contests. Mimeo.

Becker G.S. (1974) A theory of social interactions. Journal of Political Economy 82: 1063-1093.

Becker G.S. (1976) Altruism, egoism, and genetic fitness: economics and sociobiology. Journal of Economic Literature 14: 817-826.

Bergstrom T.C. (1995) On the evolution of altruistic ethical rules for siblings. American Economic Review 85: 58-81.

Bergstrom T.C., Stark O. (1993) How altruism can prevail in an evolutionary environment. American Economic Review, Papers and Proceedings 83: $149-155$.

Bester H., Güth W. (1998) Is altruism evolutionarily stable? Journal of Economic Behavior and Organization 34: 193-209.

Bruce N., Waldman M. (1990) The rotten-kid theorem meets the Samaritan's dilemma. Quarterly Journal of Economics 105: 155-165.

Frank R.H. (1987) If homo economicus could choose his own utility function, would he want one with a conscience? American Economic Review 77: 593-604.

Frank R.H. (1988) Passions within reason. W.W. Norton, New York.

Glazer A., Hassin R. (1988) Optimal contests. Economic Inquiry 26: $133-143$. 
Güth W., Yaari M.E. (1992) An evolutionary approach to explain reciprocal behavior in a simple strategic game. In: Witt U. (ed.), Explaining process and change - approaches to evolutionary economics. University of Michigan Press, Ann Arbor, 23-34.

Huck S., Oechssler J. (1999) The indirect evolutionary approach to explaining fair allocations. Games and Economic Behavior 28: 13-24.

Lindbeck A., Weibull J. (1988) Altruism and time consistency: the economics of fait accompli. Journal of Political Economy 96: 1165-82.

Lohmann S., Oechssler J., Wärneryd K. (2001) Evolution and the social dilemma. Mimeo.

Mui V.-L. (1995) The economics of envy. Journal of Economic Behavior and Organization 26: 311-336.

Samuelson L. (1997) Evolutionary games and equilibrium selection. MITPress, Cambridge. 


\section{CESifo Working Paper Series}

(for full list see www.cesifo.de)

759 Chandima Mendis, External Shocks and Banking Crises in Developing Countries: Does the Exchange Rate Regime Matter?, August 2002

760 Bruno S. Frey and Lars P. Feld, Deterrence and Morale in Taxation: An Empirical Analysis, August 2002

761 Lars Calmfors and Åsa Johansson, Nominal Wage Flexibility, Wage Indexation and Monetary Union, August 2002

762 Alexander R. W. Robson and Stergios Skaperdas, Costly Enforcement of Property Rights and the Coase Theorem, August 2002

763 Horst Raff, Preferential Trade Agreements and Tax Competition for Foreign Direct Investment, August 2002

764 Alex Cukierman and V. Anton Muscatelli, Do Central Banks have Precautionary Demands for Expansions and for Price Stability? - Theory and Evidence, August 2002

765 Giovanni Peri, Knowledge Flows and Knowledge Externalities, August 2002

766 Daniel Friedman and Nirvikar Singh, Equilibrium Vengeance, August 2002

767 Sam Bucovetsky and Michael Smart, The Efficiency Consequences of Local Revenue Equalization: Tax Competition and Tax Distortions, August 2002

768 Tapio Palokangas, International Labour Market Regulation and Economic Growth with Creative Destruction, August 2002

769 Rudi Dornbusch, The New International Architecture, September 2002

770 Hans-Werner Sinn, Weber's Law and the Biological Evolution of Risk Preferences: The Selective Dominance of the Logarithmic Utility Function, September 2002

771 Thomas Mayer, The Macroeconomic Loss Function: A Critical Note, September 2002

772 Seppo Honkapohja and Kaushik Mitra, Learning Stability in Economies with Heterogenous Agents, September 2002

773 David Laidler, Inflation Targets Versus International Monetary Integration - A Canadian Perspective, September 2002

774 Morten I. Lau, Panu Poutvaara, and Andreas Wagener, The Dynamic Cost of the Draft, September 2002

775 Steven Brakman, Harry Garretsen, and Charles van Marrewijk, Locational Competition and Agglomeration: The Role of Government Spending, September 2002 
776 Anke S. Kessler and Christoph Lülfesmann, The Theory of Human Capital Revisited: On the Interaction of General and Specific Investments, September 2002

777 Kjell Erik Lommerud, Frode Meland and Lars Sørgard, Unionized Oligopoly, Trade Liberalization and Location Choice, September 2002

778 Antonio Merlo and François Ortalo-Magné, Bargaining over Residential Real Estate: Evidence from England, September 2002

$779 \mathrm{Yu}-\mathrm{Fu}$ Chen and Michael Funke, Exchange Rate Uncertainty and Labour Market Adjustment under Fixed and Flexible Exchange Rates, September 2002

780 Michael S. Michael, International Migration, Income Taxes and Transfers: A Welfare Analysis, September 2002

781 Clemens Fuest and Alfons Weichenrieder, Tax Competition and Profit Shifting: On the Relationship between Personal and Corporate Tax Rates, October 2002

782 Jan Bouckaert and Hans Degryse, Softening Competition by Enhancing Entry: An Example from the Banking Industry, October 2002

783 Johann K. Brunner and Susanne Pech, Adverse Selection in the Annuity Market with Sequential and Simultaneous Insurance Demand, October 2002

784 Gregory D. Hess and Eduard Pelz, The Economic Welfare Cost of Conflict: An Empirical Assessment, October 2002

785 Jan Erik Askildsen, Uwe Jirjahn, and Stephen C. Smith, Works Councils and Environmental Investment: Theory and Evidence from German Panel Data, October 2002

786 Geir H. Bjønnes, Dagfinn Rime, and Haakon O. Aa. Solheim, Volume and Volatility in the FX-Market: Does it matter who you are?, October 2002

787 John Evans and John Fingleton, Entry Regulation and the Influence of an Incumbent Special Interest Group, October 2002

788 Wolfgang Ochel, International Comparisons and Transfer of Labour Market Institutions, October 2002

789 B. Gabriela Mundaca, Moral Hazard Effects of Bailing out under Asymmetric Information, October 2002

790 Gene M. Grossman and Edwin L.-C. Lai, International Protection of Intellectual Property, October 2002

791 John Hassler, José V. Rodriguez Mora, Kjetil Storesletten, and Fabrizio Zilibotti, A Positive Theory of Geographic Mobility and Social Insurance, October 2002 
792 Paul De Grauwe and Marianna Grimaldi, The Exchange Rate in a Model with Heterogeneous Agents and Transactions Costs, October 2002

793 Guido Friebel and Mariassunta Giannetti, Fighting for Talent: Risk-shifting, Corporate Volatility, and Organizational Change, October 2002

794 Jan Erik Askildsen, Badi H. Baltagi, and Tor Helge Holmås, Will Increased Wages Reduce Shortage of Nurses? A Panel Data Analysis of Nurses' Labour Supply, October 2002

795 Marko Köthenbürger and Panu Poutvaara, Social Security Reform and Intergenerational Trade: Is there Scope for a Pareto-Improvement?, October 2002

796 Paul De Grauwe and Laura Rinaldi, A Model of the Card Payment System and the Interchange Fee, October 2002

797 Volker Böhm and Tomoo Kikuchi, Dynamics of Endogenous Business Cycles and Exchange Rate Volatility, October 2002

798 Mariam Camarero, Javier Ordóñez, and Cecilio Tamarit, The Euro-Dollar Exchange Rate: Is it Fundamental?, October 2002

799 Misa Tanaka, How Do Bank Capital and Capital Adequacy Regulation Affect the Monetary Transmission Mechanism?, October 2002

800 Jörg Baten and Andrea Wagner, Autarchy, Market Disintegration, and Health: The Mortality and Nutritional Crisis in Nazi Germany, 1933-1937, October 2002

801 Saku Aura, Uncommitted Couples: Some Efficiency and Policy Implications of Marital Bargaining, October 2002

802 Wolfram F. Richter, Delaying Integration of Immigrant Labor for the Purpose of Taxation, October 2002

803 Gil S. Epstein and Shmuel Nitzan, The Politics of Randomness, October 2002

804 John Hassler and José V. Rodriguez Mora, Should UI Benefits Really Fall over Time?, October 2002

805 Friedrich Breyer and Stefan Felder, The Dead-anyway Effect Revis(it)ed, October 2002

806 Assar Lindbeck and Solveig Wikström, E-exchange and the Boundary between Households and Organizations, November 2002

807 Dieter Bös, Contests Among Bureaucrats, November 2002

808 Steven Brakman, Harry Garretsen, and Marc Schramm, The Strategic Bombing of German Cities during World War II and its Impact on City Growth, November 2002

809 Florian Englmaier and Achim Wambach, Contracts and Inequity Aversion, November 2002 
810 Sarbajit Sengupta, Delegating Recruitment under Asymmetric Information, December 2002

811 Rajshri Jayaraman, On the Partial Public Provision of a Private Good, December 2002

812 Stéphanie Stolz, Banking Supervision in Integrated Financial Markets: Implications for the EU, December 2002

813 Christian Keuschnigg, Taxation of a Venture Capitalist with a Portfolio of Firms, December 2002

814 Inés Macho-Stadler and David Pérez-Castrillo, Settlement in Tax Evasion Prosecution, December 2002

815 Rainer Niemann and Dirk Simons, Costs, Benefits, and Tax-induced Distortions of Stock Option Plans, December 2002

816 Jan-Egbert Sturm and Barry Williams, Deregulation, Entry of Foreign Banks and Bank Efficiency in Australia, December 2002

817 V. Anton Muscatelli, Patrizio Tirelli, and Carmine Trecroci, Monetary and Fiscal Policy Interactions over the Cycle: Some Empirical Evidence, December 2002

818 Claude Hillinger, A General Theory of Price and Quantity Aggregation and Welfare Measurement, December 2002

819 Erkki Koskela and Ronnie Schöb, Optimal Capital Taxation in Economies with Unionised and Competitive Labour Markets, December 2002

820 Sheilagh Ogilvie, Guilds, Efficiency, and Social Capital: Evidence from German ProtoIndustry, December 2002

821 Hans Gersbach and Verena Liessem, Financing Democracy, December 2002

822 Costas Hadjiyiannis, Panos Hatzipanayotou, and Michael S. Michael, Optimal Tax Policies with Private-Public Clean-Up, Cross-Border Pollution and Capital Mobility, December 2002

823 François Ortalo-Magné and Sven Rady, Homeownership: Low Household Mobility, Volatile Housing Prices, High Income Dispersion, December 2002

824 Syed M. Ahsan and Panagiotis Tsigaris, Measuring the Social Discount Rate under Uncertainty: A Methodology and Application, December 2002

825 Kai A. Konrad, Altruism and Envy in Contests: An Evolutionarily Stable Symbiosis, December 2002 